\title{
Adapting realist synthesis methodology: The case of workplace harassment interventions
}

\author{
Tracey Carr ${ }^{1}$ (D) | Elizabeth Quinlan ${ }^{2}$ | Susan Robertson ${ }^{2}$ | Angie Gerrard ${ }^{2}$
}

\author{
${ }^{1}$ Department of Community Health and \\ Epidemiology, University of \\ Saskatchewan, 107 Wiggins Road, \\ Saskatoon, SK S7N 5E5, Canada \\ ${ }^{2}$ Department of Sociology, University of \\ Saskatchewan, Canada

\section{Correspondence} \\ Tracey Carr, Department of Community \\ Health and Epidemiology, 107 Wiggins \\ Road, University of Saskatchewan, \\ Saskatoon, SK S7N 5E5, Canada. \\ Email: tracey.carr@usask.ca
}

Realist synthesis techniques can be used to assess complex interventions by extracting and synthesizing configurations of contexts, mechanisms, and outcomes found in the literature. Our novel and multi-pronged approach to the realist synthesis of workplace harassment interventions describes our pursuit of theory to link macro and program level theories. After discovering the limitations of a dogmatic approach to realist synthesis, we adapted our search strategy and focused our analysis on a subset of data. We tailored our realist synthesis to understand how, why, and under what circumstances workplace harassment interventions are effective. The result was a conceptual framework to test our theory-based interventions and provide the basis for subsequent realist evaluation. Our experience documented in this article contributes to an understanding of how, under what circumstances, and with what consequences realist synthesis principles can be customized.

\section{1 | INTRODUCTION}

The methodology of realist synthesis for complex interventions has been articulated in reporting standards and guiding principles. ${ }^{1,2}$ In this paper, we outline how we adapted realist synthesis techniques to identify the necessary theory from the expansive and heterogeneous workplace harassment intervention literature. More specifically, our realist synthesis assembled and rigorously synthesized the literature on workplace harassment interventions to make visible the mechanisms by which these interventions in various contexts can reduce workplace harassment. Using critical realist synthesis methodology $^{3,4}$ we extracted the causal statements involved in interventions in workplace harassment, which comprise elements of program-level theory. By consolidating these program-level theory elements, we generated a conceptual platform (ie, a coherent set of provisional propositions that suggests how harassment interventions are meant to effect change) to explain the relationship between the contexts within which interventions are implemented and the mechanisms by which the interventions work to reduce harassment. Our ultimate goal is to use the conceptual platform in a subsequent stage to formulate hypotheses to be tested in an intervention directed at reducing workplace harassment. Building on the realist synthesis results, we will use realist evaluation in the future test of an intervention to understand what works, why, and in what manner in various contexts.

Our synthesis diverged from the standardized version of realist syntheses ${ }^{2}$ by following iterative searches down idiosyncratic pathways. Following Jagosh et al, ${ }^{5}$ we hold there is not a single approach to realist synthesis but rather a set of principles that often need to be tailored. Our need to customize arose because of (1) the nature of the literature we were examining, in which theory is seldom explicitly identified, and (2) our previously developed theoretical framework, which contained macro-level critical social theory.

In this paper, we first delineate types of realism (scientific vs critical) and situate ourselves within the critical realist camp. Our allegiance to critical realism has implications for our understanding of the mechanisms 
regarding workplace harassment interventions. Next, we outline our targeted iterative literature searches and screening criteria used to derive the sources for the conceptual platform. By illustrating the distinctive iterative, flexible nature of realist syntheses, and how theory-building particularly necessitates such plasticity in approach, this paper contributes to an understanding of how, under what circumstances, and with what consequences realist synthesis principles can be customized. A detailed account of the platform and the implications for testing the program-level theory will be fully elaborated in a future paper. By way of example the paper argues for the importance of aligning substantive theory with the particular stream of realism underpinning the methodology used in a review.

\section{2 | BACKGROUND}

Workplace harassment is identified with considerable negative consequences for individuals ${ }^{6-13}$ and organizations, all of which have significant fiscal implications. ${ }^{14,15}$ Regardless of these substantial organizational and personal costs, agreement on the causes and mechanisms of harassment remain contentious. These competing and often contradictory propositions concerning the causes of harassment have led to an array of intervention types on the part of governments, employers/managers, and unions to eliminate the personal, organizational, and cultural effects of harassment within public and private sector workplaces. Despite a proliferation of workplace harassment interventions, ${ }^{16}$ there is minimal research identifying, testing, and refining the theories accounting for how and why particular interventions work, for whom and under what circumstances. The purpose of our realist synthesis of the workplace harassment intervention literature was to respond to this gap.

In our scoping review ${ }^{17}$ of workplace harassment interventions in health care organizations, we found that the most promising results were reflected in interventions based on participatory principles to include employees from all levels of the organization in the co-creation of intervention goals and implementation as well as their evaluation strategies. This scoping review prompted our interest in understanding how, why, and under what circumstances interventions reduce harassment in all workplaces, not simply those in the health care sector. Such a query corresponds clearly with realist methodology.

\section{3 | THEORETICAL CONTEXT}

Available to the realist synthesis was our alreadyformulated theoretical framework, comprised of components of critical social theory, but without theory specific to the problem context of the social relations within contemporary workplaces. One component of the framework sits Marx's historical materialism with its premise that human societies are differentiated by the nature of work performed by humans to produce the means of their subsistence and the social relations embedded in those forms of production. ${ }^{18}$ In the capitalist mode of production, labor is the variable cost for the capitalist, in contrast to the fixed costs of materials, buildings etc., so in order to reduce the variance in labor costs, the capitalist seeks to control the labor process. ${ }^{19}$

Another component of the macro-level theory is Habermas's reconstruction of Marx's historical materialism by his substitution of social interaction for work as the defining characteristic of the human activity. ${ }^{20,21}$ Habermas's reconstruction captures the specificity of the social and cultural dimensions that inevitably shape the nature and experience of social life-what Marx, especially overly deterministic readings of Marx, is unable to provide. Habermas's theory of social transformation charts a 2-sided character of contemporary institutions differentiating between system and lifeworld. The system is composed of the formally organized social relations steered by money and administrative power. The lifeworld, a resource for workers to develop their social connections, consists of 3 elements: culture (meanings circulating within the workplace as symbols, language, beliefs, values, norms); social connections (enduring patterns of action and interaction among people who share a culture and occupy a common space); and, self-identities of employees within the workplace. The system, based on the demands of material production, operates on the principles of efficiency, calculability, predictability, and control. In Habermas's view, at this stage of societal evolution, the system increasingly colonizes the lifeworld, with the ill-effect of distorting communicative activity. Habermas emphasized the autonomous development of communicative rationality, as a feature of the lifeworld, and as an antidote to the system colonization.

We determined that if we could identify a theory specific to the problem context (ie, workplaces), we would then be better positioned to capture the social mechanisms that Mayntz ${ }^{22}$ describes as causal propositions. These causal propositions explain how certain outcomes manifest under certain conditions. Similar to Mayntz, we envisage such propositions or mechanisms as linear or non-linear, observable or non-observable, many or standalone. Our intent is not to discover universal meanings but rather perceive regularities in the relationships between micro-phenomena and macro-phenomena. 


\section{4 | EMPLOYING REALIST SYNTHESIS TECHNIQUES}

A relatively new theory-driven approach, realist synthesis produces or identifies middle-range theories-theories that remain close to the empirical phenomenon but allow for generalizations - for a detailed and practical understanding of complex social interventions. ${ }^{22}$ Realist synthesis does so by asking the following questions: "what works, how, for whom, in what circumstances and to what extent?" Whether theoretical assumptions are explicit or implicit, realist syntheses involve an integrative examination of program-level theory and evidence to build middle-range theory. Realist synthesis presents an ideal way to investigate advances in the new field of interventionbased research on workplace harassment, as the methodology is designed to rigorously identify the breadth of heterogeneous literature regarding complex interventions to reveal how and why interventions are effective (or not). A key insight of realist synthesis is that particular interventions may work well in 1 type of workplace (eg, levels of harassment are reduced, workers' well-being is improved), but poorly or not at all in another type of workplace.

Developed by Pawson and colleagues, ${ }^{1}$ who identified a need for evaluation of complex social interventions, realist synthesis is intended to explain how interventions work (or do not work). Realist syntheses enable more than a simple answer to whether an intervention is successful but also allow consideration of the vital interplay of context and outcome. Realist synthesis permits knowledge of intervention outcomes, and an understanding of the context within which the outcomes are possible and the mechanisms that produce the outcomes, all of which can be used to inform policymakers and assist researchers to design subsequent robust studies.

\section{1 | Realism streams}

The 2 streams of realist synthesis draw from different interpretations of Bhaskar's philosophy of critical realism. ${ }^{23}$ Pawson and Tilley's ${ }^{24}$ scientific realism embraces the pragmatism of piecemeal social engineering, averting normative dimensions. An alternative stream, articulated by Porter and colleagues, ${ }^{3,4}$ argues that realist evaluation research requires explicitly articulated ethical positions and assessments of interventions based on how well they support human needs, capacities, and potentials. We place ourselves in the latter stream because it aligns with our founding substantive theory rooted in critical social theory.
Bhaskar's critical realism articulates a best practice for critical social theory precisely because both have strong emancipatory impulses. In line with Porter, we hold that unless explicitly critical, realist evaluation research can all too easily obscure ethical dimensions behind descriptive categories thereby making the results amenable to technocratic instrumentalism and devaluation of lifeworlds, a process antithetical to the Habermasian component of our macro-level theory. Moreover, Marx's own definition of critical theory as "the self-clarification of the struggles and wishes of the age" (1843) commands that we acknowledge our theoretical framework as straightforwardly political in cast.

Associated with the differing streams of realist synthesis is the debate concerning the definition of program mechanisms. Whereas Pawson and Tilley ${ }^{24}$ define mechanisms in terms of people's reasonings and the resources that allows them to engage those reasonings, Porter $^{3}$ understands mechanisms as generative powers that "are consciously created by agents with the aim of altering interpretations and actions of others" and that "result from the distribution of material, cultural, and jurisdictional resources embedded in social relations" (p. 77). Porter's definition of mechanisms excludes people's reasoning to locate them solely in the structural realm. We are informed by Porter's definition because it accords with our substantive theory's focus on the structures that coordinate social activities.

We were also informed by Mayntz's ${ }^{22}$ discussion of mechanisms in macro-phenomena. According to Mayntz, the causal relations between macro-phenomena can be understood in "the actions of different actors" (p. 252)that is, social mechanisms are reflected in the combined actions of individuals. Workplace harassment interventions are embodied by such combined actions.

\section{2 | Embarking on realist synthesis steps}

Our realist synthesis involved several iterative steps that deviate from a conventional realist protocol in 2 important ways. Namely, we conducted a citation analysis of key theoretical articles and a theory-based targeted search. While we kept with the realist protocol by first establishing a search strategy, then screening the data and extracting essential elements of the data (ie, explanatory accountsEAs), followed by synthesizing/consolidating the EAs, we found it necessary to add these novel components to our process in order to keep to our purpose of understanding the theoretical basis of workplace harassment interventions. Our intent was for our synthesis to provide the basis of an empirical test (ie, a realist evaluation) by developing a theory-informed conceptual platform. 


\subsection{1 | Search strategy}

In the face of considerable breadth and diversity of the harassment literature, our search was conducted by a team of academics ( 3 content specialists and 1 librarian), identified as senior researchers and 5 graduate students. Under the guidance of the team's librarian, we pursued several search strategies to find literature reporting workplace harassment interventions in all industrial sectors, from primary, construction, and manufacturing industries to service sector workplaces. The 4 separate strategies comprised the following: (1) an aggregate search of several pertinent databases; (2) a delineated search of the database most salient to our topic (Sociological Abstracts); (3) a citation analysis of key sources found in Sociological Abstracts; and (4) a targeted search for literature related to the theory specific to the problem context and needed for our conceptual platform.

Before the formal literature search began, we undertook a thorough background search on existing reviews (ex: systematic, scoping, realist) of workplace harassment interventions to ensure our proposed research was novel, and there was, in fact, a gap to fill. This preliminary search for existing relevant reviews spanned 8 sources including the Cochrane Library, the Campbell Collaboration Library of Systematic Reviews, and Google Scholar. The results were reviewed by the team, and 4 were analyzed in detail for relevancy to our particular study. ${ }^{7,16,25}$ Each of these 4 reviews was in the area of workplace harassment interventions; however, they did not fill the above-identified gap. Three of the 4 were systematic, rather than realist reviews. Although the fourth source ${ }^{26}$ was a realist review, it was limited to the health care sector in the UK. However, it did inspire our search strategy to consist of 3 main concepts: harassment, the workplace, and interventions.

The search terms were piloted in a database indexing literature of the team's home discipline (sociology) to ensure the search strategy was retrieving relevant results. Sociological Abstracts was selected to test and validate the proposed search strategy. During the pilot, the librarian revised the search strategy based on feedback from the senior and junior team members. Once finalized, the search strategy was then used in the formal literature search process.

The vast and diverse workplace harassment literature reflects a multiplicity of perspectives from the applied disciplines of Business, Public Administration, and Social Work through to theoretical disciplines such as Sociology and Psychology. We selected databases specific to these theoretical and applied disciplines, as well as databases which were more multi-disciplinary in scope. In total, 11 databases were searched in mid-June 2015: ABI/Inform
Complete, Academic Search Complete, CBCA Complete, PAIS International, ProQuest Dissertations \& Theses Global, PsycINFO, Scopus, Social Services Abstracts, SocINDEX, Sociological Abstracts, and the Web of Science.

The summary of the search results is illustrated in Figure 1. During the second search strategy, an article surfaced that significantly affected the direction and scope of the review. This pivotal article prompted the 2 subsequent searches-the citation analysis and the targeted theory search. After iterative screening phases, 33 articles were retained, and their data were extracted and synthesized for populating our conceptual platform. Each of these phases is described later.

\subsubsection{Aggregate search}

The aggregate search, excluding sources from Sociological Abstracts, produced 11263 references, and the de-duplication of these sources resulted in 9215. In the next step, as a strategy to ensure inter-rater reliability, we divided the results into 3 groups and worked in pairs ( 1 junior and 1 senior researcher) to apply the 5-point screening criteria to the titles and/or abstracts of the sources. These criteria were as follows: (1) harassment must involve those who are in employed by the workplace (to the exclusion of harassment by such individuals and groups as clients or patients); (2) the source must propose, describe, or study a harassment-focused intervention (defined as a concerted organized effort to address workplace harassment); (3) the source must be related to work-based harassment (eg, harassment in schools may be included if research addresses harassment among staff, but not if it relates to child harassment); (4) the source must consider faceto-face harassment and not cyber-harassment (although the study can consider cyber-harassment and face-to-face harassment); and (5) the source must be written in English.

The combined result of the initial screening by the 3 senior-junior pairs was 1042 references. After a further elimination process of non-academic sources that did not meet the inclusion criteria, the final tally was 732 references. The non-academic sources (eg, trade journal articles and brief reports) were separated for use in a future phase of the research, during which hypotheses emanating from the conceptual platform will be developed and tested through examination of the gray literature.

\subsection{3 | Sociological abstracts search}

The aggregate search excluded Sociological Abstracts not by our design but because of a technical difficulty, whereby the database would consistently time-out prior 


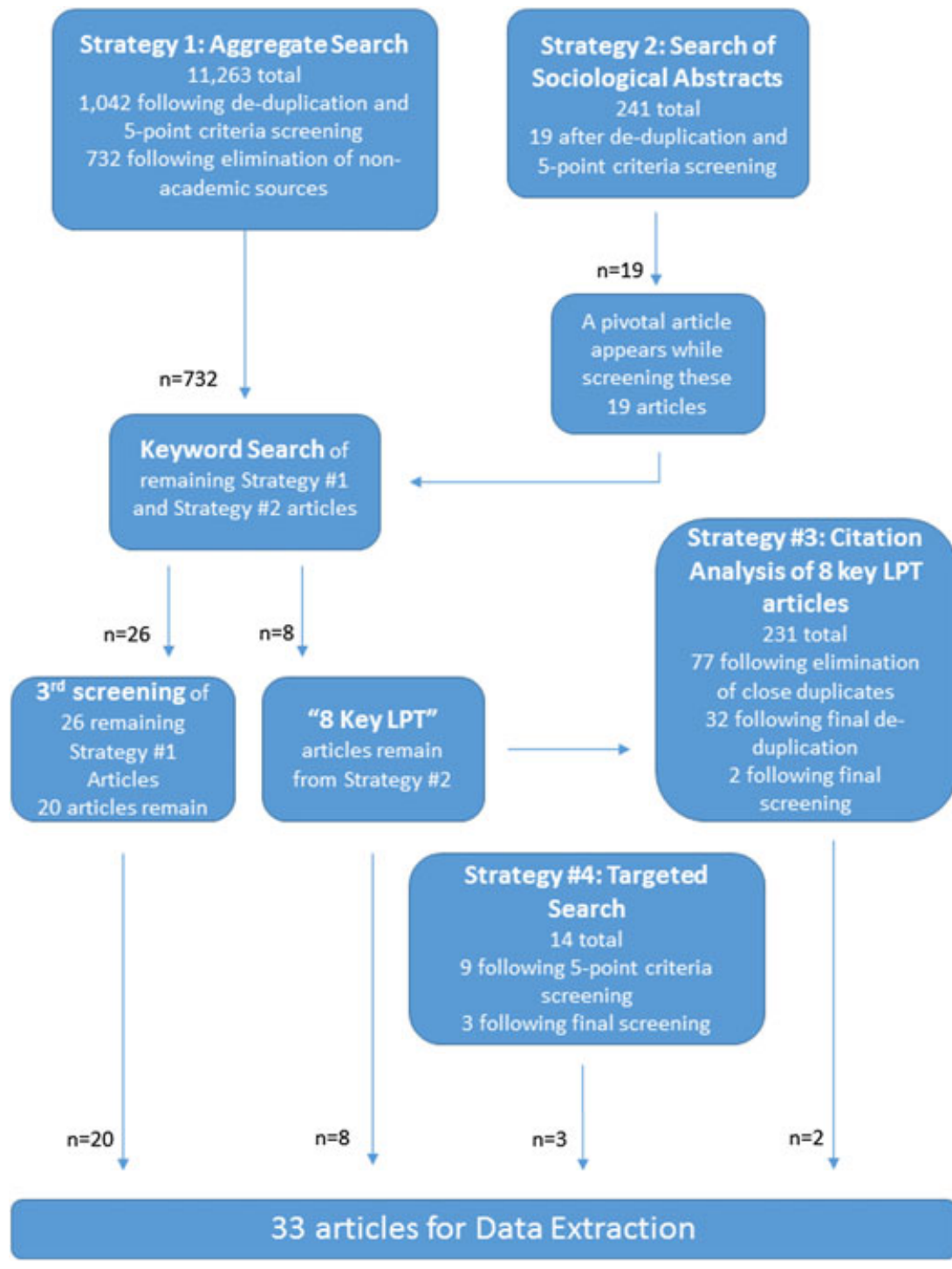

FIGURE 1 Summary of search results [Colour figure can be viewed at wileyonlinelibrary.com] to the download of all references. The consequence of the unforeseen technical problem was a subset of references (ie, from Sociological Abstracts) that needed to be treated as a separate search in terms of de-duplication, selection, and data extraction. The additional compensatory steps introduced considerable non-linearity to the review process. When the technical difficulty with Sociological Abstracts was resolved, the results of searching that database were 241 references. De-duplication and application of the inclusion criteria reduced this number to 19. While reviewing the 19 Sociological Abstracts references, we made a serendipitous discovery. ${ }^{27}$ Uncovering a pivotal article altered subsequent steps of the review in 2 crucial ways, as described in the subsequent sections.

\section{A pivotal article surfaces}

An article that applied the perspective of labor process theory (LPT) to workplace harassment ${ }^{27}$ guided us to the theory previously missing from our foundational theoretical framework. Put forward by Braverman, ${ }^{28}$ LPT contemporarizes Marx's analysis of the structural antagonism within the relationship between employers and employees, arising from the exploitation of labor for profit under the present-day capitalist mode of production. Understood within the frame of LPT, workplace harassment is a function of the convergence of several historical trends that affect the way work is organized under contemporary capitalism. More specifically, workplace harassment can be a form of managerial control, complementing restructuring, performance management systems, work intensification, and other dominant forms of managerial control in neoliberal workplaces. The perspective introduces the notion that in certain contexts harassment can benefit employers through their greater control of the workforce. Easily hypothesized contexts would include the secondary labor markets of the highvolume industries characterized by high turnover and low-paid workforces. 
LPT is also consistent with the second prong of our theoretical scaffold, Habermasian theory of social transformation, outlined earlier. As social institutions, workplaces are subject to the dualistic tendencies of system and lifeworld rationalization. On the one hand, the administrative power radiating from the prioritizing of cost efficiencies over all other aspects of productive processes is a manifestation of system rationalization. System rationalization, if left unchecked by the lifeworld, results in alienation, domination, and communication between individuals that is no longer oriented by a discourse ethic, which is the moral foundation of communicative action among workers. Distorted communication patterns, such as harassment, are harmful consequences. On the other hand, the rising income inequality, declining quality of life for multitudes of workers, and a flourishing anti-egalitarian character of workplaces have opened a space to lifeworld rationalization and greater receptivity to new needs and concerns of workers.

Lastly, and importantly, LPT accords with a critical realist view of harassment as causally governed by mechanisms that sustain the exploitation of labor power, but these do not always bring about observable workplace harassment. Correspondingly, we cannot assume that the absence of empirically observable harassment implies that the causes of the harassment are also absent.

\subsection{4 | A further screening by LPT keywords}

With consideration of LPT, we conducted an additional screening process of 732 references from the aggregate search and 19 references from Sociological Abstracts. To adequately re-screen the results for vestiges of LPT, we developed keywords, expressive of the main tenets of the theory, and applied them to the remaining 732 and 19 references from step 1 and 2, respectively. Eight references remained from the Sociological Abstracts, which we dubbed the 8 key LPT articles and used them in the citation analysis (described later). Twenty-six references remained from the aggregate database search where careful reading of these by senior researchers reduced the number to 20 .

\subsection{5 | Citation analysis}

With so few search results rooted in the theory of LPT, we conducted a cited reference searching to determine sources that had cited our 8 key LPT articles and where there was overlap between these sources. Each of the 8 articles was searched in Web of Science, Scopus, and Google Scholar. Once this cited reference search was completed and de-duplicated, all references totalled 231. To see where the overlap was between the sources, the team reviewed all the duplicates $(n=73)$ and discovered that of these, 23 references were located in 2 articles, and 9 in 3 articles. No references were in more than 3 articles. Therefore, the unique number of references was 32 .

Next, we analyzed whether each article had adopted, built upon, made cursory mention of, or rejected LPT. This analysis indicated there were very few overlaps and cross-referencing within the body of LPT-inspired literature on harassment (see Table 1). Only 9\% built upon and $17 \%$ adopted the theory. The majority (74\%) of the citations were cursory mentions of LPT. The limited interconnections within the body of literature, that is the sparseness of the literature's net, are reflected in the low numbers of the 4 categories of articles in the citation analysis (see Table 1).

Not surprisingly, the 2 oldest $\operatorname{articles}^{29,30}$ were the most commonly cited of the 8 key articles. The majority of the 32 cited precisely these 2 , providing further evidence of the pioneer status of these 2 articles. The most recently published of the LPT articles ${ }^{31}$ attracted no

TABLE 1 Results of citation analysis

\begin{tabular}{|c|c|c|}
\hline \multirow{2}{*}{\multicolumn{2}{|c|}{ Adoption of the 8 key LPT articles }} & \multirow{3}{*}{$\begin{array}{l}\begin{array}{l}\% \text { of all } \\
\text { citations }\end{array} \\
17\end{array}$} \\
\hline & & \\
\hline $\begin{array}{l}\text { \# of adopted } \\
\text { articles }\end{array}$ & $\begin{array}{l}\text { \# of adopting } \\
\text { articles }\end{array}$ & \\
\hline 1 & 5 & \\
\hline 2 & 4 & \\
\hline 3 & 1 & \\
\hline \multicolumn{2}{|c|}{ Building upon on the 8 key LP articles } & 9 \\
\hline $\begin{array}{l}\text { \# of articles } \\
\text { built upon }\end{array}$ & $\begin{array}{l}\text { \# of building } \\
\text { articles }\end{array}$ & \\
\hline 1 & 1 & \\
\hline 2 & 3 & \\
\hline \multicolumn{2}{|c|}{ Cursory mention of the 8 key LP articles } & 74 \\
\hline $\begin{array}{l}\text { \# of articles } \\
\text { mentioned cursorily }\end{array}$ & $\begin{array}{l}\text { \# of cursorily mentioning } \\
\text { articles }\end{array}$ & \\
\hline 1 & 5 & \\
\hline 2 & 13 & \\
\hline 3 & 5 & \\
\hline 4 & 3 & \\
\hline \multicolumn{2}{|c|}{ Rejection of the 8 key LP articles } & 0 \\
\hline $\begin{array}{l}\text { \# of articles } \\
\text { rejected }\end{array}$ & $\begin{array}{l}\text { \# of rejecting } \\
\text { articles }\end{array}$ & \\
\hline 0 & 0 & \\
\hline Total citations & & 100 \\
\hline
\end{tabular}


citations, confirming the important effect of time-in-print on articles' citations.

Two of the 8 key LPT articles were themselves included in the 32 found through the citation analysis, both built upon the 2 pioneering LPT articles. ${ }^{28,29}$ Only 2 of the 8 LPT articles cited each other. Because it is theoretically possible for any of the 8 to cite each other, we take the low inter-citing count as another indication of the uncongested sparse nature of the LPT literature net, within which there is very limited cross-fertilization.

\subsection{6 | Targeted search}

A fourth and final search strategy, stimulated by the paucity of labor-process oriented articles, entailed a targeted search for literature. The search covered the 11 databases using a simple Boolean search of the 2 main concepts: labor/LPT and workplace harassment (and related synonyms). When the search found less than 5 results, it was revised to remove the word theory. Fourteen unique references resulted. After the 14 references were screened with the 5-point criteria, 9 remained, from which 3 were selected via a careful reading by the senior researchers.

\section{3 | Data extraction: Identifying elements of program-level theory-The explanatory accounts}

The extraction phase, conducted by the senior researchers, involved an analysis of the 33 references: 20 from the aggregate search, the 8 key LPT articles, 2 from the citation analysis, and 3 from the targeted search (see Figure 1). The data extracted were causal statements of program-level theory, that is, the enabling/ constraining factors of the interventions and the impact of those factors on triggering mechanisms that produce the single outcome of reduction in harassment. To isolate specific EAs, we looked for words and for phrases that indicated causal links. For example, in adapting text from Everton, Jolton, and Mastrangelo, ${ }^{32}$ we developed the following EA: If managers and organizations are perceived to be fair and supportive, then there will be fewer and

TABLE 2 Constructing a consolidated account

\begin{tabular}{|c|c|c|}
\hline Source of explanatory account & Explanatory account $(n=3)$ & Consolidated account \\
\hline Dupré \& Barling ${ }^{35}$ & $\begin{array}{l}\text { If employees perceive interpersonal injustice } \\
\text { in relations with supervisors (eg, degree to } \\
\text { which employees feel they are treated with } \\
\text { respect, dignity, sensitivity, and courtesy), } \\
\text { they may be motivated to re-establish a } \\
\text { sense of justice by retaliating against the } \\
\text { source of injustice }\end{array}$ & $\begin{array}{l}\text { Perceptions of injustice are a central element in the } \\
\text { subjective experience of bullying and because } \\
\text { different organizational contexts, occupations, } \\
\text { and countries affect the threshold for what is } \\
\text { considered unjust (ie behaviors that a } \\
\text { "reasonable" person would expect perpetrators } \\
\text { could and should have avoided-Note: The } \\
\text { element of "reasonable" person means that } \\
\text { bullying is not entirely a subjective experience). } \\
\text { Social and cultural factors affect employees' } \\
\text { perceptions of when managers and colleagues } \\
\text { could and should have acted differently }\end{array}$ \\
\hline
\end{tabular}

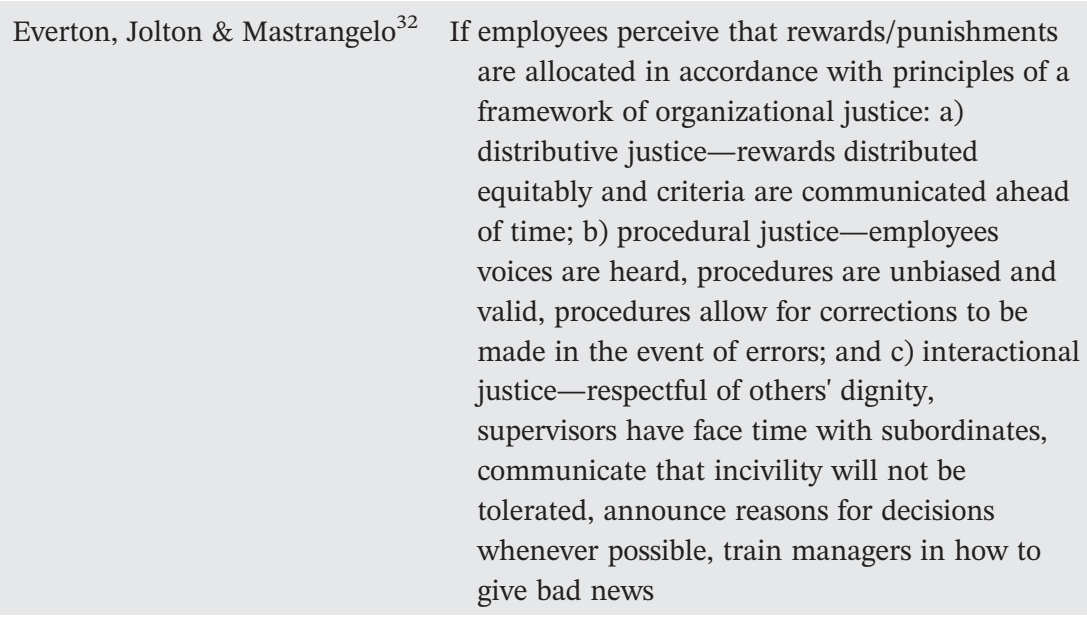

Ogunfowora $^{36}$

\section{Consolidated account}

subjective experience of bullying and because different organizational contexts, occupations, and countries affect the threshold for what is considered unjust (ie behaviors that a "reasonable" person would expect perpetrators e: The bullying is not entirely a subjective experience). could and should have acted differently
If abusive supervision varies, it creates negative attitudes toward the supervisor independently of the individual experience of abuse 
less severe incidents of bullying in the workplace. These causal statements constituted the program theory elements. Numbering 98, these EAs were then consolidated for synthesis into a conceptual platform.

\section{4 | Data consolidation}

Similar to other phases of the synthesis, the consolidation phase required an amalgamation of methods from various authors. To synthesize the extracted EAs, we drew on the techniques of Pearson et $\mathrm{al}^{33}$ and Rycroft-Malone et $\mathrm{al}^{34}$ first categorizing the accounts as either theoretical (thick accounts ${ }^{34}$ ) or empirical accounts, then using a collective, deliberative process involving face-to-face lengthy sessions of the 3 senior researchers purposefully challenging and debating each other's assertions. In accordance with one of the key purposes of a synthesis-to compare theory to actual practice-we first dealt with the theoretical accounts by considering each one individually, deliberating on whether it represented a novel account or an elaboration or contradiction of one already identified. ${ }^{33}$ Once the theoretical EAs were consolidated, we perused the empirical EAs, one by one, to determine whether they added to the already consolidated theoretical accounts or presented a unique causal statement. The results were 24 consolidated accounts (CAs). Further consolidation of the 24 accounts was achieved by (1) amalgamating accounts with overlapping content and (2) consolidating non-contradictory CAs that detail mechanisms related to the same program/intervention. Table 2 outlines how 1 $\mathrm{CA}$, containing the mechanism perceptions of injustice, was constructed from 3 EAs.

\section{5 | CONCLUSION}

Our development of a conceptual platform for workplace harassment interventions through a realist lens of iterative literature searches and use of critical realist perspectives demonstrates the adaptability and applicability of realist synthesis techniques. This realist synthesis of harassment intervention literature is one of the first studies of its kind. It was a first step toward the team's overarching goal of developing, testing, and refining theory on how harassment interventions work, for whom, and under what circumstances. The conceptual platform will be used in a subsequent stage to formulate hypotheses to test in a workplace harassment intervention.

To develop the conceptual platform, we diverged from typical realist synthesis procedures with the idiosyncratic citation analysis and targeted search arising from a serendipitous discovery of an LPT article. Along with Jagosh et $\mathrm{al}^{5}$ we found that customizing the research synthesis method can be time consuming and potentially fraught with conceptual challenges but is sometimes necessary. While we began our searches with a general knowledge of literature on workplace harassment interventions, and macro-level theory, it was not until we discovered a relevant theory well into our literature search that we felt our base was sturdy enough to facilitate the extraction and consolidation of the EAs. Although we eventually did uncover the missing component in our theoretical framework, it did require that deviation from the projected steps of the review.

Our starting point for our realist synthesis was the macro-level theory of Marx's historical materialism and Habermas's theory of communicative action: the latter being a reconstruction of the former to emphasize ethical communicative processes. As a sociological theory in the critical tradition, LPT is the only one that explains the problem context and is consistent with this macro-level scaffolding. For overall coherence, aligning levels of theory seemed crucial, as it would for any realist review. Yet, to our knowledge, such alignment has not been discussed in the realist literature, a surprising gap given its claim to being a theory-driven approach.

In addition to being consistent with our macro-level theory, LPT is congruent with a critical realist view of harassment. Despite a growing recognition of harassment among scholars, managers, and governments, it is still largely understood to stem from the personality traits of the harasser. ${ }^{7}$ Such a limited understanding of harassment is not consistent with the realist synthesis methodology's requirement for an accounting of the complex, multi-faceted nature of social problems for which interventions are to be developed and evaluated.

In contrast to the behaviorist theories, LPT amplifies the social dimension of the problem of harassment and its solution and helps to explain why the problem of harassment persists. It challenges the notion that it is in the interests of employers to eliminate harassment and the even stronger assumption that employers have the capacity to eliminate it, despite the conspicuous compromise to productivity and profits. In certain contexts, harassment can benefit employers through the control of the workforce, particularly in the secondary labor markets with the high-volume production and service industries with low-paid workforces prone to rapid turnover. This is not to suggest that all harassment interventions are ill-fated, but particular doubt is cast on the potential of top-down strategies (eg, workplace policies, legislation).

By way of example, the paper argues that the development of a fulsome theoretical framework is necessary for intervention testing and that such development can require deviating from standardized realist synthesis steps. In approaching realist synthesis, researchers can 
be encouraged to adapt search strategies and pursue novel techniques in their analysis of the literature.

\section{ACKNOWLEDGEMENTS}

We gratefully acknowledge the contributions of the following student researchers: Dani Robertson-Boersma, Chanda Hetzel, Natasha Miller, Hakim Shokoya, and Quaid Bettschen.

\section{ORCID}

Tracey Carr ${ }^{\circledR}$ http://orcid.org/0000-0003-1309-6702

\section{REFERENCES}

1. Pawson R, Greenhalgh T, Gill H, Walshe K. Realist review-a new method of systematic review designed for complex policy interventions. J Health Serv Res Policy. 2005;10:21-34.

2. Wong G, Greehalgh T, Westhorp G, Buckingham J, Pawson R. RAMESES publication standards: realist syntheses. BMC Med. 2013;65(5):1005-1022.

3. Porter S. The uncritical realism of realist evaluation. Evaluation. 2012;21(1):65-82.

4. Porter S, O'Halloran P. The use and limitations of realistic evaluation as a tool for evidence-based practice: a critical realist perspective. Nurs Inq. 2012;19(1):18-28.

5. Jagosh J, Pluye P, Wong G, et al. Critical reflections on realist review: insights from customizing the methodology to the needs of participatory research assessment. Research Synthesis Methods. 2014;5(2):131-141.

6. Ayoko OB, Callan VJ, Härtel CEJ. Workplace conflict, bullying, and counterproductive behaviors. International Journal of Organizational Analysis. 2003;11(4):283-301.

7. Hodgins M, MacCurtain S, Mannix-McNamara P. Workplace bullying and incivility: a systematic review of interventions. International Journal of Workplace Health Management. 2014;7(1):54-72.

8. Hoel H, Faragher B, Cooper CL. Bullying is detrimental to health, but all bullying behaviours are not necessarily equally damaging. British Journal of Guidance and Counselling. 2004;32(3):367-387.

9. Hutchinson M, Vickers MH, Jackson D, Wilkes L. Bullying as circuits of power: an Australian nursing perspective. Administrative Theory \& Praxis. 2010;32(1):25-47.

10. Kivimäki M, Virtanen M, Vartia M, Elovainio M, Vahtera J, Keltikangas-Järvinen L. Workplace bullying and the risk of cardiovascular disease and depression. Occup Environ Med. 2003;60:779-783.

11. Waldman JD, Kelly F, Sanjeev A, Smith HL. The shocking cost of turnover in healthcare. Healthcare Management Review. 2004;29:2-7.

12. Wykes T, Whittington R. Reaction to assaults. In: Wykes T, ed. Violence and Health Care Professionals. London: Chapman \& Hall; 1994:105-126.
13. Zapf D, Knorz C, Kulla M. On the relationship between mobbing factors and job content, social work environment, and health outcomes. Eur J Work Organ Psy. 1996;5(2):215-238.

14. Barber C. Use of bullying as a management tool in healthcare environments. Br J Nurs. 2012;21(5):299-302.

15. Porath CL, Pearson CM. The Cost of Bad Behaviour: How Incivility is Damaging your Business and What to Do About it. New York: Penguin Group; 2009.

16. Gillen P, Sinclair M, Kernohan WG, Begley CM, Luyben AG. Interventions for prevention of bullying in the workplace. Cochrane Database Syst Rev. 2012;4: Art. No.: CD009778. https://doi.org/10.1002/14651858.CD009778.pub2

17. Quinlan E, Robertson S, Miller N, Robertson-Boersma D. Interventions to reduce bullying in health care organizations: a scoping review. Health Serv Manag Res. 2014;27(1):33-44.

18. Marx K. Capital: A Critique of Political Economy, Volume I. London: Lawrence \& Wishart; 1867.

19. Marx K. Wage, Labour, and Capital. New York: International Publishers; 1933.

20. Habermas J. The Theory of Communicative Action: Reason and the Rationalization of Society (trans T. McCarthy). Boston: Beacon Press; 1984.

21. Habermas J. Moral Consciousness and Communicative Action (trans. C. Lenhard and S.W. Nicholsen). Cambridge, Massachusetts: MIT Press; 1996.

22. Mayntz R. Mechanisms in the analysis of social macro-phenomena. Philos Soc Sci. 2004;34:237-259.

23. Bharskar R, Callinicos A. Marxism and critical realism. Journal of Critical Realism. 2003;1(2):89-114.

24. Pawson R, Tilley N. Realistic Evaluation. London: Sage; 1997.

25. Rittenmeyer L, Huffman D, Hopp LJ, Block M. A comprehensive systematic review on the experience of lateral/horizontal violence in the profession of nursing. The JBI Database of Systematic Reviews and Implementation Reports. 2013;11(11):362-468.

26. Illing JC, Carter M, Thompson NJ, et al. Evidence synthesis on the occurrence, causes, consequences, prevention and management of bullying and harassing behaviours to inform decisionmaking in the NHS. Final report. NIHR Service Delivery and Organization programme. 2013.

27. Beale D, Hoel H. Workplace bullying, psychological perspectives and industrial relations: towards a contextualized and interdisciplinary approach. British Journal of Industrial Relations. 2011;16(2):101-118.

28. Braverman H. Labor and Monopoly Capital: The Degradation of Work in the Twentieth Century. New York: Monthly Review Press; 1974.

29. Ironside M, Seifert R. Tackling bullying in the workplace: the collective dimenion. In: Einarsen S, Hoel H, Zapf D, Cooper C, eds. Bullying and Emotional Abuse in the Workplace: International Perspectives in Research and Practice. London: Taylor \& Francis; 2003:383-398.

30. Lewis D, Rayner C. Bullying and human resource management: a wolf in sheep's clothing? In: Einarsen S, Hoel H, Zapf D, Cooper C, eds. Bullying and Emotional Abuse in the Workplace: 
International Perspectives in Research and Practice. London: Taylor \& Francis; 2003:370-382.

31. Saundry R, McArdle L, Thomas P. Reframing workplace relations?: conflict resolution and mediation in a primary care trust. Work Employ Soc. 2013;27(2):213-231.

32. Everton W, Jolton J, Mastrangelo P. Be nice and fair or else: understanding reasons for employees' deviant behaviours. J Manag Dev. 2007;26(2):117-131.

33. Pearson M, Brand SL, Quinn C, et al. Using realist review to inform intervention development: methodological illustration and conceptural platform for collaborative care in offender mental health. Implement Sci. 2015;10(1):134-146.

34. Rycroft-Malone J, McCormack B, Hutchinson AM, et al. Realist synthesis: illustrating the method for implementation research. Implement Sci. 2012;7(1):33.
35. Dupré K, Barling J. Predicting and preventing supervisory workplace aggression. $J$ Occup Health Psychol. 2006;11(1):13-26.

36. Ogunfowora B. When the abuse is unevenly distributed: the effects of abusive supervision variability on work attitudes and behaviors. Journal of Organizational Behavior. 2013;34(8):1105-1123.

How to cite this article: Carr T, Quinlan E, Robertson S, Gerrard A. Adapting realist synthesis methodology: The case of workplace harassment interventions. Res Syn Meth. 2017;8:496-505. https://doi.org/10.1002/jrsm.1261 